\title{
Marie de Gournay \\ Escritos sobre la igualdad y en defensa de las mujeres
}

\author{
Cristina Ambrosini ${ }^{1}$
}

cristinaambrosini@gmail.com

Rec. 19/02/2018, Apr. 27/04/2018

\section{Un libro de la mano de una feminista}

En la actualidad, a nivel mundial, se encuentran instalados en la sociedad las temáticas de género. Es un lugar común señalar la lucha de la mujeres por derecho conculcados desde hace siglos. En el campo de la filosofía la situación de la mujer no difiere de otros contextos sociales y su invisibilidad es notoria. Decimos "invisibilidad", porque no es que no hayan existido mujeres notables en el

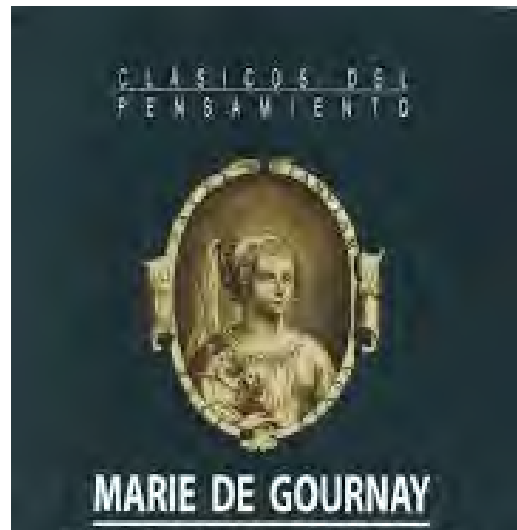

ESCRTTOS SOBRE LA IGUALDAD Y EN DEFENSA DE LAS MUIERES

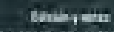

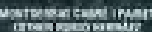

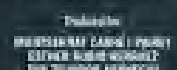

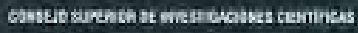
mundo de las ideas, pero la cultura patriarcal les ha quitado reconocimiento.

El 8 de marzo de 2018 se programó una Jornada de Paro de mujeres, de alcance mundial, que tuvo masiva adhesión en nuestro país. Pocos días antes de esa fecha, el 20 de febrero, recibimos en la UNLa la visita de la Dra. Concha Roldan, incansable defensora de los Derechos de las mujeres y estudiosa de la Historia de las luchas por los reclamos de igualdad entre los sexos. Este encuentro tuvo como escenario acorde al tema el Cine Universitario Tita Merello, con una conferencia cuyo título fue Invisibilidad y exclusión histórica de las mujeres. Consecuencias ético-politicas actuales. La Dra. Roldán se refirió a casos históricos donde las voces de distintas mujeres filósofas, científicas, escritoras y pensadoras de distintas épocas históricas han sido invisibilizadas, acalladas, desestimadas como protagonistas de la cultura y el pensamiento de su época. La disertación no se limitó a la referencia histórica de la presencia de estas mujeres sino que profundizó en las consecuencias de esta exclusión en el plano ético-político. La Dra. Roldán aludió específicamente al caso de Marie de

1 Cristina Ambrosini es Dra. en Filosofía y Directora de la Epsecialización y de la MAestríe en Metodología de la Investigación Científica de la UNLa. Es profesora asociada de la cátedra de Introducción al Pensamiento científico en la UBA. 
Gournay y a la edición de sus obras en castellano como un modo de restaurar el valor de estas protagonistas de la cultura. De modo que, en concreto, las voces de estas mujeres están siendo recuperadas también por la publicación de sus escritos como es el caso del libro que nos entregó en donación donde por primera vez se publica en castellano cuatro escritos seleccionados de la obra de Marie de Gournay (1565-1645), Escritos sobre la igualdad y defensa de las mujeres, publicado por el Centro Superior de Investigaciones Científicas de España de donde es Directora del Instituto de Filosofía ${ }^{2}$. Este libro es un logro que resulta de la voluntad de los editores por presentar en lengua castellana textos fundamentales de la filosofía occidental invisibilizados y por lo tanto acallados en la tradición. Dados a conjeturar, podemos ver que estas presencias silenciadas lo han sido por la corrosiva crítica que encontramos en estos textos. El caso de Marie de Gournay resulta paradigmático ya que tuvo mayor trascendencia como "hija de adopción" de una gran figura como Michel de Montaigne, como editora de sus obras, que como escritora con autonomía y valor propio. Una vez más, una mujer legltimó su lugar por estar acompañando el nombre de un hombre ilustre. Con el libro que estamos comentando vemos que Marie de Gournay fue más que eso, fue una de las pocas voces que en la primera modernidad aludió a los derechos de las mujeres, denunció las inequidades existentes y promovió un debate que motorizó el pensamiento de su época. Antes de llegar a este tema, aludiremos a su figura al lado del que luego será el padre de la literatura francesa y un pilar de la tradición escéptica en filosofía.

\section{Marie, fille d'alliance de Michel de Montaigne}

El nombre de Marie de Gournay es reconocido por los estudiosos de la obra de Michel de Montaigne como la editora de los Ensayos. Lo que resulta menos conocido es el modo en que una mujer llegó a tener esta responsabilidad a fines del Siglo XVI. En 1588 a la edad de 55 años Michel de Montaigne (1533-1592) conoce en París a Marie Le Jars de Gournay (1565-1645), una joven de 23 años, con vocación de escritora, quien al enterarse de su cercanía le envió una carta donde le contó que lo leía desde hacía unos años. Al día siguiente Montaigne concurrió a la cita. ¿Qué puede haber decidido a Montaigne a aceptar conocerla? Cualquiera sea la respuesta a este interrogante lo cierto es que el mensaje llegó a destino y marcó la vida de ambos. Luego de este primer encuentro se queda viviendo con ella seis meses en su propiedad en Gournay-sur-Aronde, al norte de París, una propiedad rural con una casona de dos pisos pomposamente considerada como un chateaux. Luego mantienen hasta la muerte de Montaigne una relación ambigua donde él reconoce que es su hija de elección pero que su sentimiento va más allá del amor fraternal. En el libro II, capítulo XVII, en la edición de Marie de los Ensayos, puede leerse:

He tenido gran placer en publicar en varios lugares la esperanza que tengo en Marie de Gourmay, mi hija de alianza, a la que por cierto amo mucho más que paternalmente, integrada en mi retiro y soledad como una de las mejores partes de mi propio ser. A nadie en el mundo considero más que a ella. (Montaigne, 2011, p. 605)

2Cabré i Pairet, Montserrat y Rubio Herráez, Esther (Eds.), Marie de Gournay. Escritos sobre la igualdad y en defensa de las mujeres, Centro Superior de Investigaciones Científicas, Madrid, 2014. 
¿Cuál es el alcance de ese "mucho más”? Las respuestas recorren un arco de posibilidades entre los que incluso creen que esa frase fue agregada por la misma Marie en la versión a su cargo de los Ensayos. Antes que Marie, Montaigne gozó de la amistad de mujeres poderosas, incluso como persona de confianza y de confidencias. Para la época ejerció su influencia sobre la misma Reina madre, Catalina de Médicis, viuda de Enrique II, de Margarita de Valois, hija de Catalina, hermana de Enrique III y esposa de Enrique de Navarra, el futuro sucesor del reino de Francia. Otra amiga poderosa en la corte de la época fue Corisande d'Andoins, esposa de un hombre rico y mujer cercana al mismo Enrique de Navarra. Montaigne tiene algo afín a las mujeres, las seduce con citas en latín y griego, gusta rodearse de ellas. En esta cercanía consigue información privilegiada que contribuye a cumplir su papel como componedor moderado, prudente, negociador hábil entre facciones enfrentadas por motivos religiosos que no son más que la pantalla de los intereses de las potencias vecinas por hacer de Francia un país protestante mientras que los católicos y el Vaticano dan batalla para que esto no se consiga. A mediados del Siglo XVI, Burdeos es un territorio estratégico cuando Montaigne por voluntad del mismo Enrique III es nombrado alcalde de su ciudad. Nunca antes ni después estuvo Francia tan cerca de pasar a ser un país protestante. La noticia del nombramiento le llega cuando está en Roma en 1581 y se toma su tiempo para regresar y asumir funciones. Así es que el rey instala un católico moderado, de eficaz llegada al vecino rey protestante de Navarra, un intelectual de valor probado por la publicación de los Ensayos que fueron del agrado del monarca pero que, por otro lado, levantaron las alertas rojas de las censuras del poder papal. Finalmente, ya no lo verá Montaigne, pero en 1676 el Vaticano colocará a los Ensayos en la lista de Los libros prohibidos.

Por su parte Marie, en ese primer encuentro, le cuenta que literalmente enloqueció cuando leyó una versión que le llegó de los Ensayos a los 17 o 18 años, que le dijeron que su autor ya estaba muerto y que se enteró que no solamente era falso que estuviera muerto sino que al igual que ella estaba en París por lo que decide mandarle una carta. Michel recibió este mensaje entusiasta donde se transluce el apasionamiento de la joven hacia su obra escrita, lo único que verdaderamente le importa que trascienda luego de su muerte. Inmediatamente, como dijimos, concurre a la cita para conocerla, al lugar donde se hospedaba con su madre. El escritor chileno Jorge Edwards (2011) afirma que Marie es la joven que todo escritor maduro espera encontrar en el final de su vida, alguien dispuesto a consagrar su vida a colaborar, a ordenar, a reescribir y alguien a quien legarle el cuidado de la obra luego de muerto. Ella estudia afanosamente, con los escasos recursos de la biblioteca de su casa, para estar a la altura al menos del conocimiento del latín, algo vedado para las mujeres. Marie aparece como una colaboradora, una fuente de inspiración, una albacea elegida antes del final. Dejar la obra en buenas manos cuando ya no esté sobre la tierra parece ser la principal preocupación de Montaigne en esta etapa de su vida a juzgar por el resultado de la lectura de la carta de Marie.

El vínculo con Marie remeda otro con el amigo que marcó su vida, Étienne de La Boétie (1530-563). El último día que pasan junto en Gournay-sur-Aronde, Montaigne lo dedica a leerle historias de amor escritas por Plutarco. Antes de despedirse por última vez le regala a Marie un diamante con una M inscripta en el reverso (Edwards, 2011, p. 243).

Como Ulises, como Eneas, un día debe volver a sus tierras donde lo reclaman múltiples deberes. Él es el señor del que dependen muchas vidas. La de Marie se sostendrá durante los siguientes cuatro años en la devoción por el intercambio epistolar y en escribir una novela que lo tiene como protagonista. Ya no volverán a verse. Cuando Montaigne 
agrava su dolencia, le manda una carta a través de Pierre de la Brousse uno de los hermanos pero no llega a destino. Ella se entera de la muerte de su amado padre adoptivo nueve meses después del deceso. Luego viaja al castillo donde es recibida por la viuda y su única hija quienes encuentran en esta fille d'alliance a la hija y a la hermana adoptiva en la que delegarán el cuidado y ordenamiento de la biblioteca y los Ensayos. Ellas también ahora la adoptan como un familiar. El mismo cardenal Richelieu, años después, apoya a esta mujer empecinada en hacer de su padre intelectual, el padre de la literatura francesa y en 1635 le otorga una pensión vitalicia.

Como en el inglés de Shakespeare y el español de Cervantes, el francés de Montaigne será una obra fundamental de la literatura universal. Aquí, como en tantos otros casos, se produce una grieta entre los defensores de la versión de los Ensayos de Marie y sus críticos pero ella lo sabe y los enfrenta ya desde el Prólogo. Después de todo está autorizada para hacerlo, ella es la responsable de la versión oficial de los Ensayos, delegada por el propio autor en su testamento. Algunos denuncian que varios párrafos son intervenciones de ella, especialmente donde habla de su hija adoptiva elogiosamente. Pero la misión de Marie no termina ni se consuma solamente en la recuperación de los Ensayos. Para estar a la altura de su padre adoptivo, ella se ocupa de escribir y publicar su propia versión del mundo.

Las biografías de Montaigne destacan la presencia del amigo, Etienne de La Boétie, y silencian la de la amiga. No casualmente será la apropiación republicana de "La servidumbre voluntaria" la que hará famoso a su autor. Del resto, no dice nada y otra vez Marie estará en el lugar de esa presencia silenciada, acallada, negada, puesta en un lugar anecdótico, ocasional. Su propia obra como escritora necesitará de otros dos o tres siglos para ser estudiada y valorada independientemente de su peculiaridad como curadora de los Ensayos. En el Prólogo, donde suscribe como "Su hija de alianza", adopta el papel de protagonista, se refiere a él como "mi padre", incluso exagera en los elogios a la viuda "por haber cumplido los deberes de un ardiente amor conyugal a la memoria de su marido" y da rienda suelta a sus ideas acerca de la obra. Con un fuerte tono polémico se adelanta a quienes se burlarán de sus afanes, que no la tomarán en serio por ser mujer. Así es que se dirige, mirando fijo y de frente, a un hipotético lector, a un lector hostil, que desconfía de su intervención como editora. Lector, no acuses de temeridad el juicio favorable que había él formado sobre mí cuando adviertas en este escrito cuán lejos estoy de merecerlo. Cuando me alababa, yo lo poseía: yo con él y yo sin él somos dos cosas diferentes. No me duró sino cuatro años, no más que a él La Boétie. ¿¿Será que la fortuna, por piedad hacia los demás hombres, haya limitado tales amistades a este término, a fin de que el desprecio por un bien tan corto los guardara de comprometerse con los dolores que hay que sufrir por la privación? [...] Pues esta es la única palabra del contrato de la amistad profunda: "Tú y yo nos entregamos uno al otro porque no podríamos encontrar nada mejor en otra parte" (Montaigne, 2011, p. 36).

En tono provocativo, alude a la inferioridad de su condición sexual. Sabe que el lector de los Ensayos es un varón y que va a juzgar prejuiciosamente su intervención como editora de la obra. Casi en tono de reproche le señala las distancias:

Bien feliz eres tú, lector, si no perteneces a un sexo al que se le han prohibido todos los bienes al prohibirle la libertad, $\mathrm{y}$ al que se le han prohibido todas las virtudes al quitarle el poder, formándolas en la moderación de su uso, a fin de constituirles como única virtud y felicidad el ignorar y el sufrir. Muy feliz, que puedes ser sabio sin crimen, pues tu sexo te confiere 
toda acción, toda palabra justa y la posibilidad de ser creído o al menos escuchado. (Montaigne, 2011, p. 18)

¿Qué dicen los franceses de ella? No deja de ser una afrenta a la tradición que haya sido una mujer excéntrica, una mujer disconforme y rebelde frente al orden social, quien se ocupara de la versión oficial del padre de su literatura. A poco de publicados los Ensayos en la versión de Marie comenzaron a proliferar los críticos quienes desconfían y presentan sospechas de cambios en la versión original. Para fundamentar sus denuncias recurren al Ejemplar de Burdeos que es una versión de los Ensayos olvidada dentro de un armario desde la época anterior a Marie cuando Montaigne publicó su obra y encuentran diferencias. Es cierto que el propio Montaigne corregía, cambiaba, intercalaba y modificaba en cada nueva edición sus escritos al punto que se han encontrado varias versiones y compilaciones distintas. Cuando todavía el Derecho de autor no generaba controversias legales, eran frecuentes los plagios, los autoplagios y las distintas versiones de una misma obra. Cada vez que releía lo escrito, Montaigne agregaba frases en los márgenes, en las entrelíneas, tachaba, pegaba tiras de papel sobre lo escrito para intercalar otras frases.

Finalmente, la obra bajo su cuidado, se publicó un año antes del nacimiento de Descartes (1526) y 28 años antes del nacimiento de Pascal (1623). Después escribió sobre la igualdad entre los sexos y se la considera una de las primeras feministas dos siglos antes de la Revolución francesa y de los escritos que llevarían a la guillotina a Olympe de Gouche (1748-1793) por decir cosas parecidas a las que publicó. Actualmente es motivo de revisión y revalorización la potente influencia que ejerció Marie sobre el autor de los Ensayos luego de su paso por Gournay sur Aronde. Las compiladoras de estos textos, por primera vez traducidos al castellano, destacan que:

[...] no es aventurado suponer que el autor ha introducido cambios influido por las ideas de Marie, sobre las que discutió con ella tanto durante su estancia en Gournay sur Aronde como, probablemente, por carta. (Cabré i Pairet et alt, 2014, p. 25)

El Prólogo a los Essais fue publicado en distintas versiones, modificado por ella misma, lo que indica que fue sumamente importante no solamente para destacar la importancia de la obra de Montaigne sino como carta de presentación de sus propias ideas.

\section{Marie escritora polémica y prolífica}

Las etiquetas encubren la complejidad de toda relación. La de Marie y su padre de adopción, como dijimos, resulta inclasificable: filial, pasional, erótica, antagónica, intelectual, son calificativos que cuesta juntar. A partir del encuentro en París y de la separación seis meses después, comienza un intercambio epistolar que marcará su habilidad como escritora. De esa profusa correspondencia, que continuó por cuatro años hasta la muerte de Montaigne, no han quedado testimonios más que el anuncio de Marie, en 1596 de publicarlas pero eso nunca ocurrió. La falta de estos testimonios aumenta las especulaciones y el misterio sobre la incidencia de presiones para preservar la publicidad de este vínculo.

La primera obra como autora, independientemente del Prólogo a los Ensayos, es una novela donde el protagonista, como no podría ser de otro modo, es Montaigne. El tema 
central de la novela es el matrimonio, donde critica la desigualdad de poder para tomar decisiones, en la pareja. Le promenoir de Monsieur de Montaigne par su fille d'alliance (El paseo del Señor de Montaigne por su hija adoptiva) es el único escrito donde asume el relato de ficción, en el que imagina un cambio en las relaciones entre los sexos, donde aparece la necesidad de otorgar a las mujeres la libertad para elegir con quién casarse. De manera germinal y superpuesta al relato de ficción aparece en esta novela el interés principal de la autora por destacar el estado de desigualdad y sumisión de las mujeres, al que podrían resistirse y emanciparse si tomaran conciencia del estado de esclavitud en que se encuentran. Estas ideas acerca de la igualdad entre los sexos irán apareciendo de manera más elaborada y analítica en la prolífica obra posterior. Le promenade aparece publicado en 1594 y un año después en 1595 aparece la primera edición de los Ensayos a su cargo, con el Prólogo donde alude, como vimos, a la condición de inferioridad de las mujeres. En un tono polemista y acusador, no deja pasar la oportunidad de exponer sus ideas en el marco de la edición de la obra de Montaigne.

Luego de estar asegurada la publicación de los Ensayos, se recluye a vivir en una bohardilla en París, solamente acompañada por una asistente, para dedicarse a hacer redituable su profesión de editora exitosa. Delega el cuidado de sus propiedades en uno de sus hermanos y se dedica a ser escritora, a asistir a los salones, a estar cerca de gente influyente. Nuevamente aquí encontramos otra vez a la indómita Marie que va más allá de lo esperado, que no le importa exponerse al ridículo y al escarnio social. No conforme con apropiarse de la versión oficial de Montaigne, difunde sus propias ideas, toma una voz propia y distinta a la de su amigo-padre. La primera compilación de sus obras, donde excluye su participación en los Ensayos, fue editada en París en 1626 con el título $L$ 'ombre de la doncelle de Gournay y una reimpresión sin modificaciones se publicó al año siguiente. En 1634 agregó cinco textos más y cambia el título de las ediciones anteriores por el de Les advis ou les presens de la demoiselle de Gournay. La última recopilación de sus obras completas se publica en 1641 con el mismo título e incluye el retrato de Marie firmado por el grabador e impresor Parísino Jean Mathieu.

Con el título Escritos sobre la igualdad y en defensa de las mujeres, en esta compilación que nos entregó la Dra. Roldan, las editoras han recuperado, entre más de cuarenta obras de esta autora, cuatro de estos escritos, los que pasaremos a revisar someramente.

Igualdad de los hombres y las mujeres fue publicado en 1622 como un cuaderno de 22 páginas. Como en otras obras, se lo dedica a una mujer, Ana de Austria, desde 1615 reina de Francia por su matrimonio con Luis XIII, a la que considera una fuente de sabiduría tanto para hombres como para mujeres. Con esta referencia intenta destacar la presencia de esas mujeres poderosas como modo de restituir una genealogía femenina en la que es posible recuperar el pensamiento de muchas filósofas, poetas, provenientes algunas de la Querella de las Mujeres que puede retrotraerse al Siglo XIV, En favor de sus ideas apela justamente a autoridades reconocidas en la tradición que enfrenta como son los Padres de la Iglesia, Dios, algunos relatos bíblicos donde recupera interpretaciones favorables a su causa: la rehabilitación de las mujeres como seres pensantes en igualdad de capacidades con los hombres y como partícipes necesarias incluso en la existencia de Jesús que necesitó la mediación de un cuerpo femenino para nacer en este mundo. En este texto destaca que la única diferencia del animal-humano es el de poseer un alma racional y las diferencias sexuales solamente atañen a la procreación no a la dignidad de ser superior o inferior, "nada más parecido a un gato sobre una ventana que una gata" (p. 98) afirma con ironía haciendo con esto alusión a la falta de fundamento para se- 
ñalar diferencias intelectuales entre hombres y mujeres. Según su interpretación no es en la naturaleza donde se originan las diferencias sino en la educación y las costumbres impuestas por las leyes hechas por hombres que prefieren sostener la subordinación de las mujeres a la potestad de ellos. En su particular exégesis de la Biblia afirma que Dios dispuso la igualdad entre los sexos al hablar de su criatura como algo único.

Agravio de damas aparece en la compilación de 1626, no tuvo una publicación autónoma y es un escrito de madurez, lo escribió a los 60 ańos, donde da muestras de su gran erudición. Aquí contesta con sarcasmo e ironía a los agravios de los misóginos que aumentaron su virulencia y agresividad frente a la proliferación de mujeres aristócratas y burguesas que participan cada vez más con autonomía en la vida cultural y política. Con mayor ligereza expresiva recupera temas que valientemente había expuestos en su juventud y retoma algunos párrafos del Prólogo de los Ensayos. Comienza, como en el otro escrito de juventud, interpelando a un lector hombre, alguien que no es parte del sexo que ha sido calumniado, relegado y agraviado debido a la falta de libertad y a las prohibiciones que pesan sobre su educación y su participación en la vida social. Para ellas la ignorancia y la servidumbre han sido elevadas a la categoría de virtudes mientras se las despoja de los bienes, se les prohíbe la participación en cargos públicos e incluso eclesiásticos. Aquí Marie habla desde la experiencia personal, luego de haber sido agraviada y ridiculizada socialmente por hacer públicas sus denuncias. También Marie destaca con lucidez la actitud de las mujeres que se interesan por los escritos de los hombres, que no se sienten agraviadas por leerlos, por el contrario profundizan en comentarios de sus escritos mientras que los hombre tozudamente se obstinan en no leer lo que escriben las mujeres en un rasgo de estupidez ya que los confina en la ignorancia. Termina este escrito con una reprimenda a los hombre que desconocen lo que escriben las mujeres y les recuerda que "la ignorancia es la madre de la presunción" (p. 116).

Apología de la que escribe emula la Apología como género literario ya transitado por Montaigne en la Apología de Ramón de Sibiuda, Este breve escrito se publica por primera vez en 1626, en la primera compilación de sus obras. Aquí realiza una defensa de su reputación y un desagravio a los muchos sufridos a lo largo de su participación en los reclamos por la igualdad de las mujeres. El texto recurre nuevamente al relato autobiográfico donde la condición de ser mujer y tener una endeble posición patrimonial la sometieron a diversos tipos de vejámenes a su reputación como intelectual, a su cuestionado valor como erudita. Destaca, fuera de Francia, la buena acogida que han tenido sus escritos en los Países Bajos, en Inglaterra e Italia. Este escrito transita en una descripción de los continuos obstáculos que debe sortear una mujer que no concede en limitar su libertad por conveniencias económicas pero que a la vez debe sufrir las malas consecuencias de su actitud.

Copia de la vida de la doncella de Gournay es un texto que aunque escrito unos años antes, fue agregado en la última edición de sus Obras completas de 1641. Las compiladoras suponen que es el primer escrito autobiográfico, datado posiblemente en 1616 (p.153) y a la vez es el que cierra la última edición de sus obras completas. Nuevamente, en este escrito, alude a un ardid urdido para riduculizarla. Según nos cuenta en tercera persona, escribe esta autobiografía a pedido de unos supuestos delegados del rey de Inglaterra, Jacobo I, para ser incluido en una supuesta Antología de biografías de hombres y mujeres ilustres por su erudición, Marie, creyéndose merecedora de este sitial, entrega el escrito a estos hombres que luego utilizan para ridiculizarla ya que modificaron el texto con intervenciones que la autora consideró denigratorias de su persona. La deci- 
sión de publicar la versión original demora casi 30 años y es ubicado como colofón de sus Obras Completas, ahora precedido de una carta a un amigo, el tesorero Theveniun donde expresa la necesidad de contrarrestar el perjuicio que le ocasionó la difamación de su persona ya que siente la inminencia de su muerte. Recordemos que murió cuatro años después de esta publicación, en 1645. En este escrito encontramos datos de su linaje noble tanto por parte del padre como de la madre, de la temprana pérdida de su padre lo que acarreó las penurias económicas, de los esfuerzos por aprender por sí misma el latín a pesar del desagrado de su madre por ocuparse de temas filosóficos y científicos en lugar de prepararse como toda joven de su clase social para un matrimonio de conveniencia. Detalla en tercera persona el encuentro con su padre de adopción y luego de su muerte con su viuda e hija con las que cultivó un vínculo epistolar. En este escueto escrito de un par de páginas Marie condensa la necesidad de rehabilitar su reputación como intelectual comprometida en una lucha despareja, donde en ningún momento claudica en la defensa de sus ideas y en hacer llegar su mensaje como un legado a la posteridad.

\section{Hacer visible lo invisivilizado}

Para concluir este breve recorrido por los textos de Marie de Gournay debo destacar que lo que primero me sugieren es el reconocimiento de la irrevocable honestidad de una mujer que mantuvo a lo largo de toda su vida intelectual la mayor lealtad a sus ideas, a su afán por hacerse escuchar primero frente a su padre de adopción y luego frente a sus contemporáneos. Como otras revolucionarias, debió sufrir el escarnio y la burla de aquellos que se sintieron molestos cuando no atemorizados por la intromisión de las ideas acerca de la igualdad entre los sexos, expresadas de modo claro y contundente, como afirman las compiladoras de estos escritos (p. 171). Respecto a la edición de este libro es destacable el esmerado cuidado de las editoras en recuperar los aspectos biográficos y filosóficos que dan sentido a los escritos de Marie de Gournay para reponer las piezas faltantes en el conocimiento de una escritora autodidacta que hizo una contribución decisiva en el campo del pensamiento occidental.

Aristóteles supone que la ética tiene como condición de posibilidad (para decirlo en términos que no son aristotélicos) la presencia de modelos humanos, ejemplos sociales paradigmáticos a los que imitar. Este libro, entonces, tiene un profundo sentido ético que es el de restituir la voz de una mujer "ejemplar", una mujer que con todas las limitaciones de su época supo hacerse oir y su legado, a través de esta traducción al castellano, reinstala una figura acallada, omitida pero que una vez descubierta irradia una energía innovadora para seguir reclamando por la igualdad y en defensa de las mujeres.

\section{Bibliografía}

- Cabré i Pairet, Montserrat y Rubio Herráez, Esther (Eds.) (2014). Marie de Gournay. Escritos sobre la igualdad y en defensa de las mujeres. Madrid: Centro Superior de Investigaciones Científicas.

- Compagnon Antoine (2013). Un été avec Montaigne. Disponible en http://www. dailymotion.com/video/x141 rhk

— Edwuards, J. (2011). La muerte de Montaigne. Buenos Aires: TusQuests.

— Montaigne, M. (2011). Ensayos. Buenos Aires: Losada. 